\title{
Amazonian forest degradation must be incorporated into the COP26 agenda
}

Celso H. L. Silva Junior ${ }^{1,2,3,25 *}$, Nathália S. Carvalho ${ }^{1,2,25}$, Ana C. M. Pessôa ${ }^{1,2,25}$, João B. C. Reis $^{1,4}$, Aline Pontes-Lopes ${ }^{1,2}$, Juan Doblas ${ }^{1,2}$, Viola Heinrich ${ }^{5}$, Wesley Campanharo ${ }^{1,2}$, Ane Alencar $^{6}$, Camila Silva $^{6,11}$, David M. Lapola ${ }^{7}$, Dolors Armenteras ${ }^{8}$, Eraldo A. T. Matricardi ${ }^{9}$, Erika Berenguer ${ }^{10,11}$, Henrique Cassol ${ }^{1,2}$, Izaya Numata ${ }^{12}$, Joanna House ${ }^{5}$, Joice Ferreira ${ }^{13}$, Jos Barlow $^{11}$, Luciana Gatti ${ }^{2}$, Paulo Brando ${ }^{14,6,15}$, Philip M. Fearnside ${ }^{16}$, Sassan Saatchi ${ }^{17,18}$, Sonaira Silva $^{19}$, Stephen Sitch ${ }^{20}$, Ana P. Aguiar ${ }^{2,21}$, Carlos A. Silva ${ }^{22}$, Christelle Vancutsem ${ }^{23,24}$, Frédéric Achard $^{23}$, René Beuchle ${ }^{23}$, Yosio E. Shimabukuro ${ }^{1,2}$, Liana O. Anderson ${ }^{1,4}$, Luiz E. O. C. Aragão $1,2,20$

${ }^{1}$ Tropical Ecosystems and Environmental Sciences Laboratory (TREES), São José dos Campos, SP, Brazil

${ }^{2}$ Instituto Nacional de Pesquisas Espaciais (INPE), São José dos Campos, SP, Brazil

${ }^{3}$ Universidade Estadual do Maranhão (UEMA), São Luís, MA, Brazil

${ }^{4}$ Centro Nacional de Monitoramento e Alertas de Desastres Naturais (CEMADEN), São José dos Campos, SP, Brazil

${ }^{5}$ University of Bristol, Bristol, United Kingdom

Instituto de Pesquisa Ambiental da Amazônia (IPAM), Brasília, DF, Brazil

${ }^{7}$ Universidade Estadual de Campinas (UNICAMP), Campinas, SP, Brazil

${ }^{8}$ Ecología del Paisaje y Modelación de Ecosistemas (ECOLMOD), Universidad Nacional de Colombia (UNAL), Bogota, Colombia

${ }^{9}$ Universidade de Brasília, Brasília, DF, Brazil

${ }^{10}$ University of Oxford, Oxford, United Kingdom

${ }^{11}$ Lancaster University, Lancaster, United Kingdom

${ }^{12}$ South Dakota State University, Brookings, SD, United States

${ }^{13}$ Empresa Brasileira de Pesquisa Agropecuária (EMBRAPA) Amazônia Oriental, Belém, PA, Brazil

${ }^{14}$ University of California, Irvine, CA, United States

${ }^{15}$ Woodwell Climate Research Center, Falmouth, MA, United States

${ }^{16}$ Instituto Nacional de Pesquisas da Amazônia (INPA), Manaus, AM, Brazil

${ }^{17}$ Jet Propulsion Laboratory (JPL), Pasadena, CA, United States

${ }^{18}$ University of California, Los Angeles, CA, United States

${ }^{19}$ Universidade Federal do Acre (UFAC), Cruzeiro do Sul, AC, Brazil

${ }^{20}$ University of Exeter, Exeter, United Kingdom

${ }^{21}$ Stockholm Resilience Centre, Stockholm University, Stockholm, Sweden 
${ }^{22}$ School of Forest, Fisheries, and Geomatics Sciences, University of Florida, Florida, United States

${ }^{23}$ European Commission, Joint Research Centre (JRC), Ispra (VA), Italy

${ }^{24}$ Center for International Forestry Research (CIFOR), Bogor, Indonesia

${ }^{25}$ These authors contributed equally

*Corresponding author. Email: celsohlsj@gmail.com

To the Editor - Nations will reaffirm their commitment to reducing greenhouse gas (GHG) emissions during the 26th United Nations Climate Change Conference (COP26; www.ukcop26.org), in Glasgow, Scotland, in November 2021. Revision of the national commitments will play a key role in defining the future of Earth's climate. In past conferences, the main target of Amazonian nations was to reduce emissions resulting from land-use change and land management by committing to decrease deforestation rates, a well-known and efficient strategy $^{1,2}$. However, human-induced forest degradation caused by fires, selective logging, and edge effects can also result in large carbon dioxide $\left(\mathrm{CO}_{2}\right)$ emissions ${ }^{1-5}$, which are not yet explicitly reported by Amazonian countries. Despite its considerable impact, forest degradation has been largely overlooked in previous policy discussions ${ }^{5}$. It is vital that forest degradation is considered in the upcoming COP26 discussions and incorporated into future commitments to reduce GHG emissions.

Human-induced forest degradation is the main driver of socio-environmental impoverishment ${ }^{6,7}$ in Amazonia, and its extent is increasing ${ }^{8}$. Degraded forests currently occupy an area larger than that which has been deforested ${ }^{8,9}$. During the 2003-2015 period in the Brazilian Amazon, $\mathrm{CO}_{2}$ committed emissions from forest fires ${ }^{1}(5,904 \mathrm{Tg})$ and edge effects ${ }^{2}(2,068 \mathrm{Tg})$ reached $88 \%$ of the gross deforestation emissions ${ }^{1}\left(9,108 \mathrm{Tg}\right.$ ) (Fig. 1). Aggravating this scenario, the $\mathrm{CO}_{2}$ emissions resulting from degradation are not all immediate. Degraded forests continue to emit more $\mathrm{CO}_{2}$ than they absorb for many years, becoming significant carbon sources ${ }^{2,10}$. It is critically important for all Amazonian countries to halt these emissions. This requires reporting the whole range of $\mathrm{CO}_{2}$ emissions to the United Nations Framework Convention on Climate Change (UNFCCC), including forest degradation. If any emission source is ignored or underestimated, then the calculated amount of mitigation needed will be insufficient to prevent global warming.

Quantifying the carbon losses attributable to degradation processes is a difficult task. There are considerable uncertainties associated with degraded-forest area estimates and how each type of disturbance affects carbon fluxes. These uncertainties, however, can be reduced by combining field measurements ${ }^{7,10}$ with an ever-increasing array of remote-sensing datasets and methods that since $2005^{5}$ have enhanced our capacity to perform large-scale monitoring of degradation processes across both space and time dimensions ${ }^{1-4,8,9}$. Improved spatio-temporal estimates of forest degradation can provide valuable information to better identify and quantify degradationrelated carbon emissions. More accurate and realistic models would benefit not only the Brazilian Amazon, but also other tropical forests, directly supporting Reducing Emissions from 
Deforestation and Forest Degradation (REDD+) activities to boost the reduction of emissions worldwide.

Effective policies to curb deforestation do not directly address forest degradation ${ }^{1,2}$. In the Brazilian Amazon, while government initiatives and international pressure helped reduce emissions from deforestation ${ }^{2,11}$, emissions from forest fires ${ }^{1}$ and edge effects ${ }^{2}$ increased in the 2005-2015 period. Addressing human-induced degradation requires going beyond identifying and quantifying the different types of disturbance. Above all, new strategies must be established to avoid and offset related emissions, including the sustainable use of forest resources, restoration of degraded old-growth forests ${ }^{12}$, and protection of secondary-growth forests ${ }^{13,14}$. These strategies need to be incorporated into national policies and international agreements.

Reducing emissions from land-use and land-cover change will only be effective in supporting sustainable development of the Amazon region if policies address the social, economic, political, and environmental causes of deforestation and degradation. Furthermore, they have to be accompanied by incentives, land management technology, capacity building, provision of alternative income sources, territorial planning and market mechanisms to strengthen the sustainable production chains ${ }^{15}$. To be successful, policies that aim to address both deforestation and forest degradation must incorporate continuous on-the-ground monitoring and accountability for illegal environmental activities.

The impacts of forest degradation have been overlooked in policy discussions for too long. The COP26 discussions present an ideal opportunity to draw attention to these issues and establish much needed new strategies to reduce emissions associated with land-use and land-cover change. 7

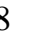
(1) 


\section{References}

1. Aragão, L. E. O. C. et al. 21st Century drought-related fires counteract the decline of Amazon deforestation carbon emissions. Nat. Commun. 9, 536 (2018).

2. Silva Junior, C. H. L. et al. Persistent collapse of biomass in Amazonian forest edges following deforestation leads to unaccounted carbon losses. Sci. Adv. 6, (2020).

3. Assis, T. O. et al. CO2 emissions from forest degradation in Brazilian Amazon. Environ. Res. Lett. 15, 104035 (2020).

4. Harris, N. L. et al. Global maps of twenty-first century forest carbon fluxes. Nat. Clim. Chang. 11, 234-240 (2021).

5. Asner, G. P. Selective Logging in the Brazilian Amazon. Science 310, 480-482 (2005).

6. Caviglia-Harris, J. et al. Busting the Boom-Bust Pattern of Development in the Brazilian Amazon. World Dev. 79, 82-96 (2016).

7. Barlow, J. et al. Anthropogenic disturbance in tropical forests can double biodiversity loss from deforestation. Nature 535, 144-147 (2016).

8. Matricardi, E. A. T. et al. Long-term forest degradation surpasses deforestation in the Brazilian Amazon. Science 369, 1378-1382 (2020).

9. Vancutsem, C. et al. Long-term (1990-2019) monitoring of forest cover changes in the humid tropics. Sci. Adv. 7, eabe1603 (2021).

10. Silva, C. V. J. et al. Estimating the multi-decadal carbon deficit of burned Amazonian forests. Environ. Res. Lett. 15, 114023 (2020).

11. Silva Junior, C. H. L. et al. The Brazilian Amazon deforestation rate in 2020 is the greatest of the decade. Nat. Ecol. Evol. 5, 144-145 (2021).

12. Lamb, D. Restoration of Degraded Tropical Forest Landscapes. Science 310, 1628-1632 (2005).

13. Heinrich, V. H. A. et al. Large carbon sink potential of secondary forests in the Brazilian Amazon to mitigate climate change. Nat. Commun. 12, 1785 (2021).

14. Smith, C. C. et al. Old-growth forest loss and secondary forest recovery across Amazonian countries. Environ. Res. Lett. (2021).

15. Stabile, M. C. C. et al. Solving Brazil's land use puzzle: Increasing production and slowing Amazon deforestation. Land Use Policy 91, 104362 (2020).

Fig. 1 | Carbon dioxide $\left(\mathrm{CO}_{2}\right)$ emissions from deforestation and forest degradation (i.e., forest fires and edge effect) within the Brazilian Amazon. (a) Annual $\mathrm{CO}_{2}$ emissions. (b) Cumulative $\mathrm{CO}_{2}$ emissions. To estimate the amount of $\mathrm{CO}_{2}$ emitted to the atmosphere by deforestation and forest degradation, we compiled data from the literature ${ }^{1,2}$ for the 2003-2015 period. The emissions by deforestation and forest fires were obtained directly from Aragão et al. (2018) ${ }^{1}$ as annual gross emission of $\mathrm{CO}_{2}$. Emissions by edge effects were calculated in two steps: (i) annual carbon (C) loss at the 120-m forest edges within the Brazilian Amazon was obtained from Silva Junior et al. $(2020)^{2}$; (ii) then, we multiplied ${ }^{1}$ all annual $\mathrm{C}$ loss by 3.67 to convert into gross $\mathrm{CO}_{2}$ emissions. 
The authors declare no competing interests.

154

\section{Acknowledgements}

This study was financed in part by the Coordenação de Aperfeiçoamento de Pessoal de Nível Superior - Brasil (CAPES) - Finance Code 001. N.S.C., A.C.M.P., J.B.C.R, P.M.F. and L.E.O.C.A. thank the Brazilian National Council for Scientific and Technological Development (CNPq) for funding (processes 140379/2018-5, 140877/2018-5, 301597/2020-0, 311103/2015-4 and 305054/2016-3, respectively). A.P.L. thanks the São Paulo Research Foundation (FAPESP; process 2016/21043-8) for funding. V.H. was supported by a NERC GW4+ Doctoral Training Partnership studentship from the Natural Environment Research Council (NE/L002434/1). D.M.L. acknowledges funding from FAPESP (2015/02537-7) and from the AIMES (Analysis, Integration and Modelling of the Earth System) program. A.A., C.S. and P.B. were funded by Global Wildlife Conservation (Grant \#5282.019-0285) and Climate Land Use Alliance (G-2010-57219). E.B. and J.B. were funded by the UK Research and Innovation (NE/S01084X/1) and the BNP Paribas Foundation (Bioclimate). J.F., E.B. and J.B. thank CNPq for funding (processes 441573/2020-7, 441659/2016-0, 441949/2018-5, and 420254/2018-8). L.O.A. thanks the Inter-American Institute for Global Change Research (IAI; process SGP-HW 016), the CNPq (processes 441949/2018-5 and 442650/2018-3), and FAPESP (processes 2016/02018-2, 2019/05440-5, and 2018/14423-4) for funding. The funders had no role in study design, data collection and analysis, decision to publish, or preparation of the manuscript. This Correspondence presents the personal views of the authors based on their scientific expertise but is not aimed at representing the official positions of their own organizations. 

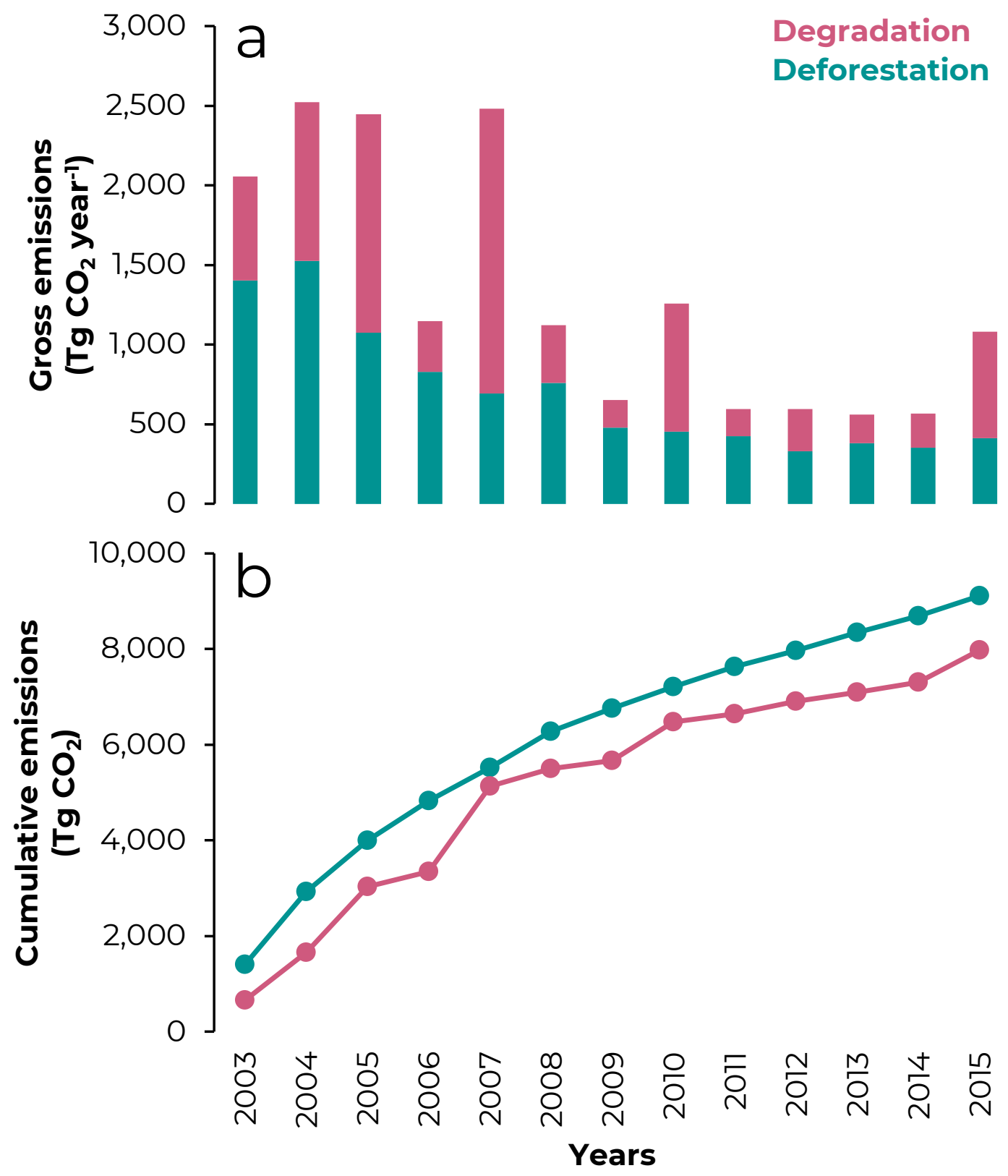